\title{
A STUDY FOR ASSESSMENT OF AWARENESS, MYTHS AND BELIEFS ABOUT EYE DONATION
}

\author{
Navneet Saxena ${ }^{1}$ \\ 1 Professor \& HOD, Upgraded Department of Ophthalmology, NSCB Medical College, Jabalpur, Madhya Pradesh.
}

\section{ABSTRACT}

\section{BACKGROUND}

The present study was conducted to assess the awareness and myths and beliefs of people about eye donation. The main objective was to assess the awareness and knowledge, willingness, myths and beliefs of people regarding eye donation.

\section{MATERIALS AND METHODS}

636 patients attending the OPD were randomly selected for a structured interview according to a questionnaire.

\section{RESULTS}

The results clearly show that $72.65 \%$ of people knew about eye donation, but only $8.21 \%$ knew when to donate eyes and only $52.05 \%$ were willing to donate eyes.

\section{CONCLUSION}

It can be concluded from the study that although people knew about eye donation, fewer people are willing to donate eyes due to various reasons. Television is the major source of information about eye donation. It can also be concluded that there is a need to educate people properly about eye donation.

\section{KEYWORDS}

Eye Donation, Blindness, Corneal Transplantation, Corneal Grafting.

HOW TO CITE THIS ARTICLE: Saxena N. A study for assessment of awareness, myths and beliefs about eye donation. J. Evolution Med. Dent. Sci. 2017;6(15):1175-1178, DOI: 10.14260/Jemds/2017/256

\section{BACKGROUND}

We see the world and receive more than $90 \%$ of knowledge through eye. Cornea, the outer coat of the eye ball, is the most valuable part of the eye. It covers the inner contents of the eyeball, protects them from infection from microbial agents and other environmental trauma. Even after this, if something goes wrong it can be managed by surgical replacement and visual acuity can be restored.

Corneal diseases constitute a significant cause of visual impairment and blindness in the developing world. According to the WHO, Visual Impairment and Blindness Fact sheet, August 2014, there are 7.8 million blind people in India and it accounts for $20 \%$ of the 285 million blind population across the world in which, $1 \%$ people are blind due to corneal blindness.[1]

Although, strategies to prevent corneal blindness are likely to be more cost effective, visual rehabilitation by corneal transplantation remains the major treatment for restoring sight in those who already have corneal blindness. Recognition of the fact that vision restoration through corneal grafting is possible for a sizable proportion of the corneal blind in India has led to a sustained multipronged drive to raise awareness of eye donations and corneal transplants.

Financial or Other, Competing Interest: None.

Submission 06-10-2016, Peer Review 20-01-2017,

Acceptance 27-01-2017, Published 20-02-2017.

Corresponding Author:

Dr. Navneet Saxena,

P-7, Doctors Colony,

Medical College Campus,

Jabalpur,

Madhya Pradesh.

E-mail:navneet03@gmail.com

DOI: $10.14260 /$ jemds $/ 2017 / 256$
After the first successful corneal transplant by Edward Zirm, it has become the most successful example of organ transplant. With the understanding of corneal anatomy and physiology, especially with regards to corneal endothelium, introduction of microsurgical technique, advances in corneal preservation, the upcoming of corneal immune suppressive agents have resulted in high success rate of corneal grafting.

Though, there has been progress in eye donation, 40,000 eyes were collected in year 2014 where target was around 2,00,000 according to National program for control of blindness 2014.[2]

The purpose of this study is to spread awareness for eye donation among people attending OPD of Netaji Subhash Chandra Bose Medical College, Jabalpur.

\section{Aims \& Objectives}

1. To determine awareness and willingness about eye donation and corneal transplant.

2. To study the effect of various myths (religion or medical) on eye donation.

3. To assess knowledge about eye donation in people.

4. To evaluate number of people who pledge for eye donation after counselling.

\section{Review of Literature}

Recognition of the fact that vision restoration through corneal grafting is possible for a sizable proportion of the corneal blind in India has led to a sustained multipronged drive to raise awareness of eye donation and corneal transplants.

Despite the fact that corneal transplantation is probably the most successful of all organ transplant procedures, offering the potential for sight restoration to those who are blind from corneal diseases and the current corneal procurement rates are inadequate to meet the transplantation needs in India. 
Knowledge of the usage of donated eyes was very poor despite reasonable, awareness of eye donation. This indicates that there is a gross inadequacy of media publicity on the entire cycle of eye donation in population. In order to transform this awareness into the pledging and procurement of more corneas, knowledge of all steps of eye donation must be increased.

According to study done by Priyadarshini B. et al in 2003, only $50 \%$ of the people interviewed had knowledge of eye donation, $20 \%$ knew about corneal transplant and only $4.34 \%$ of them knew when to donate their eyes. Lack of information could be a barrier in eye donation. [3]

It may be concluded that lack of awareness becomes a major obstacle to convince and obtain consent for eye donation. The information provided should be about-

1. When to donate eyes.

2. How to become a pledged eye donor.

3. How this pledge can be translated into actual eye donation.

4. The importance of discussing the issue with family members.

5. The importance of discussing after pledging and signing a donor card for eye donation. The public should be informed about these facts according to a study done by S. Krishnaiah, V. Kovai et al 2004.[4]

In 2005, Yew Y W, Saw S M et al conducted a study to assess the knowledge and willingness of 675 Singapore adults towards corneal donation and found that $67.0 \%$ participants were willing to donate their eyes. Ethnicity and education, religion (Christian, Hindu \& others) were associated with increased willingness to donate corneas. Awareness of corneal donation is high but specific knowledge should be further increased. ${ }^{[5]}$

A study was conducted by Bharathi M.K. et al 2009 on "awareness and knowledge on eye donation" among university students, studying first year Medicine, Dentistry, Lab Technology, Pharmacy, Biomedicine and Bioengineering degree courses in the University of Malaya were assessed on their awareness \& knowledge on eye donation using an open ended questionnaire. The results of the study indicate that there is a need to educate the young adults in our society, about corneal transplantation. So that they can in turn motivate other members of society and their own family members to become eye donors, thus facilitating the availability of donor corneas. [6]

A study was conducted by Dhaliwal U. in 2009 to assess the knowledge and attitudes of 49 final year students towards eye donation. The study concluded that controls were poorly informed about various aspects of eye donation suggesting in adequate dissemination of information. [7]

A study was conducted by Gupta A et al in 2009 on awareness and perception regarding eye donation in 188 students of nursing college in Bangalore. The majority (96.8\%) of students knew that eyes can be donated after death but only $38.2 \%$ knew that the ideal time of donation was within 6 hours of death. Most participants (85.1\%) were either willing or had already pledged their eyes. Nobility in the act of eye donation was the main motivational force for eye donation according to $85.6 \%$ of students. ${ }^{[8]}$

A preliminary survey conducted by the Aravind Eye Care system on the level of awareness of eye donation in the adult population of the state of Tamil Nadu, India found that females were less willing to pledge eyes even though they were more aware of eye donation according to World Health Assembly Document A 627/7 2009. Awareness of eye donation and willingness to pledge eyes was significantly higher among those.[9]

Another study conducted by Sulatha Bhandary, Rajesh Khanna, Krishna A. Rao et al, 2011 on attendants of 400 patients visiting various OPDs in general hospital and 2 peripheral clinics in Malaysia found that awareness of eye donation was observed in 276 (69\%) participants. Multivariate analysis showed more awareness among females. Educational status did not influence the willingness to donate eyes. It was concluded that although majority of participants were aware of eye donation, willingness to donate eyes was poor.[10]

A study was done by Manjunath S, Nekar, Laxmikant Lokare et al in 2012 to know the knowledge and attitude of 403 students from 8 colleges towards eye donation. By the survey, the research got to know that weak eye sight, religious belief, fear of invasive process and social stigma are the important reasons for not donating eyes.[11]

\section{MATERIALS AND METHODS}

This was a cross sectional study undertaken for 636 participants. Data collection was carried out via face-to-face interview based on a questionnaire in randomly selected participants attending Netaji Subhash Chandra Bose Medical College, Jabalpur.

A structured questionnaire was used to get responses to questions regarding eye donation. Source of information, awareness of corneal transplantation and religious belief were included in the questionnaire.

Questions were asked in the local language. The demographic details like age, gender, education and place of residence were also taken down by the interviewer.

Attitudes of the respondents regarding eye donation was determined through questions regarding opinions on issues such as the willingness to donate eye in future and influence of religion towards eye donation.

Practices were measured after counselling whether the subject agreed to fill the pledge form, whether the subject agreed to motivate other family members/friends to fill the pledge form of eye donation and whether the subject agreed to spread the knowledge about eye donation to others.

Literate subjects self-administered the questionnaire, whereas questions were read out to illiterates. Occupation of the subject was categorised as paramedical or nonmedical with an understanding that individuals in paramedical occupations are likely to have a better awareness compared to non-medical personnel.

\section{RESULTS}

\section{Observations}

\begin{tabular}{|c|c|c|c|c|c|}
\hline Sl. No. & Age Group & Males & Females & Total & Percentage \\
\hline 1 & $18-20$ years & 62 & 40 & 102 & $16.03 \%$ \\
\hline 2 & 21-30 years & 162 & 60 & 222 & $34.9 \%$ \\
\hline 3 & $31-40$ years & 60 & 42 & 102 & $16.03 \%$ \\
\hline 4 & $41-50$ years & 90 & 60 & 150 & $23.58 \%$ \\
\hline 5 & 51-60 years & 36 & 12 & 48 & $7.54 \%$ \\
\hline 6 & $>60$ years & 12 & 0 & 12 & $1.88 \%$ \\
\hline & Total & 422 & 214 & 636 & $100 \%$ \\
\hline
\end{tabular}




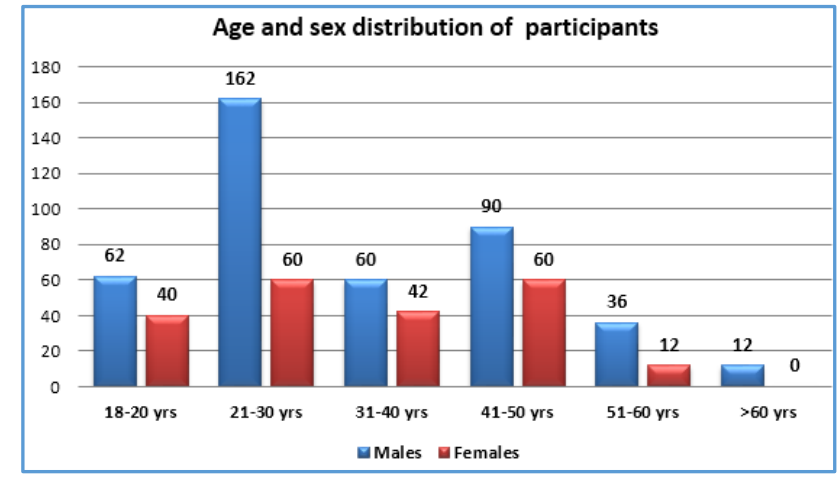

Figure 1

\begin{tabular}{|c|c|c|c|}
\hline Sl. No. & Source & No. of patients & Percentage \\
\hline 1 & Television & 204 & $46.57 \%$ \\
\hline 2 & Newspaper & 156 & $35.61 \%$ \\
\hline 3 & Internet & 54 & $12.32 \%$ \\
\hline 4 & Family Physician & 12 & $2.73 \%$ \\
\hline 5 & Family Members & 12 & $2.73 \%$ \\
\hline \multicolumn{3}{|c|}{ Table 2. Source of Information } \\
\hline
\end{tabular}

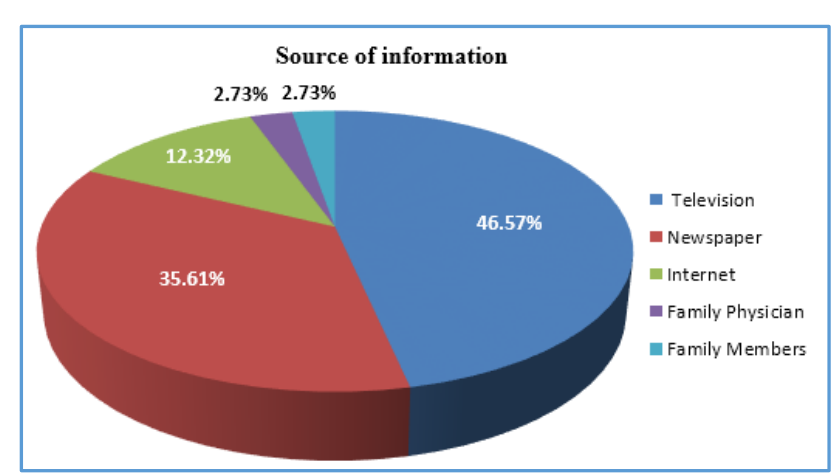

Figure 2

\begin{tabular}{|c|c|c|c|c|}
\hline Sex & $\begin{array}{c}\text { Awareness } \\
\text { (\%) }\end{array}$ & $\begin{array}{c}\text { Unawareness } \\
\text { (\%) }\end{array}$ & $\begin{array}{c}\text { Willingness } \\
\text { (\%) }\end{array}$ & $\begin{array}{c}\text { Unwillingness } \\
\text { (\%) }\end{array}$ \\
\hline Male & $\begin{array}{c}302 \\
(71.5 \%)\end{array}$ & $\begin{array}{c}120 \\
(28.43 \%)\end{array}$ & $\begin{array}{c}170 \\
(40.28 \%)\end{array}$ & 252 \\
& $(59.71 \%)$ \\
\hline Female & $\begin{array}{c}136 \\
(63.55 \%)\end{array}$ & $\begin{array}{c}78 \\
(36.45 \%)\end{array}$ & $\begin{array}{c}58 \\
(27.1 \%)\end{array}$ & 156 \\
& \multicolumn{4}{|c|}{ Table 3. Relation between Sex, Awareness \& } \\
\hline \multicolumn{4}{|c|}{ Willingness to Donate Eyes } \\
\hline
\end{tabular}

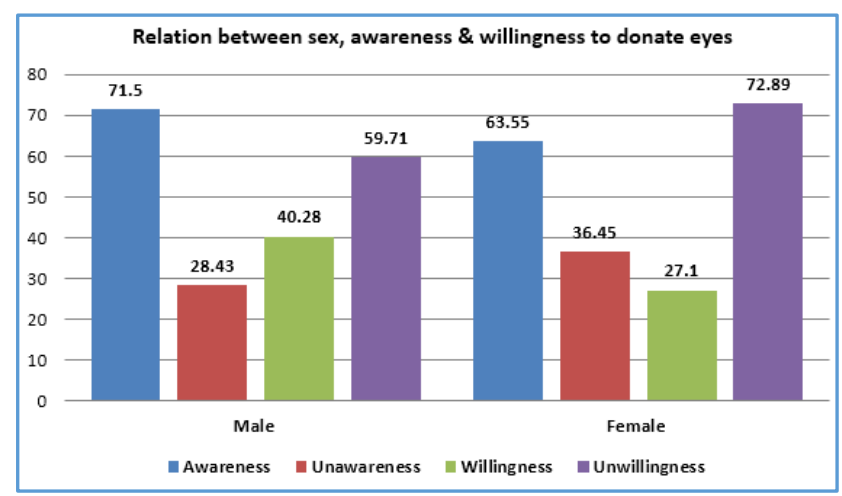

Figure 3

\begin{tabular}{|c|c|c|c|}
\hline Religion & No. of Patients & Awareness & Willing \\
\hline Hindu & 468 & 300 & 197 \\
\hline Muslim & 144 & 120 & 30 \\
\hline Sikh & 14 & 10 & 5 \\
\hline Others & 10 & 8 & 3 \\
\hline
\end{tabular}

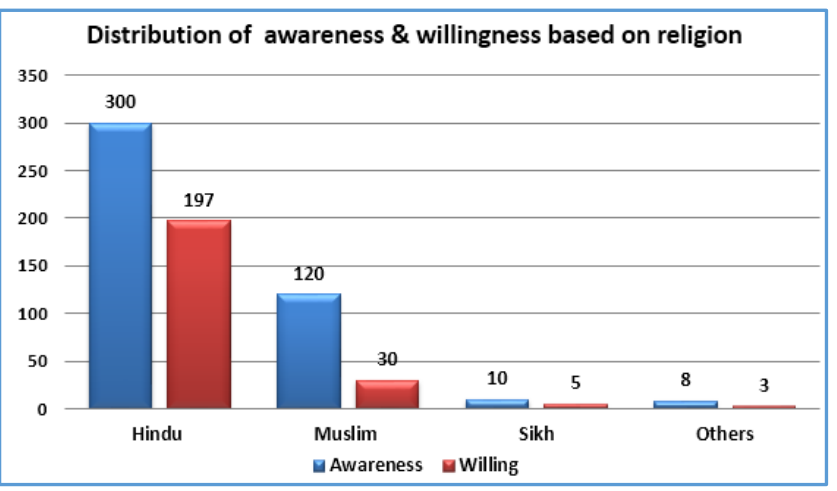

Figure 4

\begin{tabular}{|c|c|c|c|}
\hline Sl. & \multirow{2}{*}{ Participant Response } & \multicolumn{2}{|c|}{ Knowledge } \\
\cline { 3 - 4 } & Yes (\%) & No (\%) \\
\hline \multirow{2}{*}{1} & $\begin{array}{c}\text { Eyes can be removed at donor's } \\
\text { house itself }\end{array}$ & $\begin{array}{c}132 \\
(30.13 \%)\end{array}$ & $\begin{array}{c}306 \\
(69.87 \%)\end{array}$ \\
\hline \multirow{2}{*}{2} & Disfigurement of face & $\begin{array}{c}138 \\
(31.5 \%)\end{array}$ & $\begin{array}{c}300 \\
(68.5 \%)\end{array}$ \\
\hline \multirow{2}{*}{3} & $\begin{array}{c}\text { Cornea of donated eye is used } \\
\text { for transplantation }\end{array}$ & $\begin{array}{c}210 \\
(47.94 \%)\end{array}$ & $\begin{array}{c}228 \\
(52.05 \%)\end{array}$ \\
\hline \multirow{2}{*}{4} & $\begin{array}{c}\text { Agreed to motivate other family } \\
\text { members }\end{array}$ & $\begin{array}{c}540 \\
(84.9 \%)\end{array}$ & $\begin{array}{c}96 \\
(15.1 \%)\end{array}$ \\
\hline \multicolumn{3}{|c|}{$\begin{array}{c}\text { Table 5. Table showing Knowledge } \\
\text { based Response of Participants }\end{array}$} \\
\hline \multicolumn{3}{|c}{}
\end{tabular}

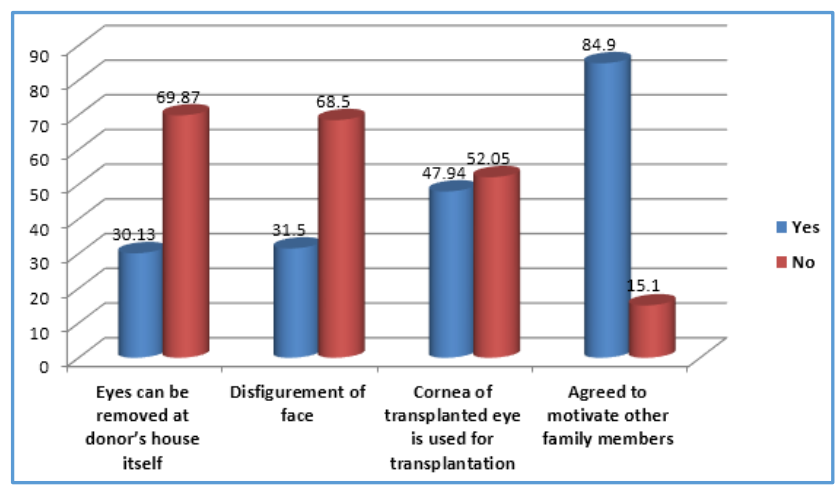

Figure 5

\section{DISCUSSION}

Data from our study suggest that additional efforts are needed to improve awareness of eye donation in the community. It is a matter of concern that only $72.65 \%$ of the persons interviewed had awareness of eye donation and only $8.21 \%$ of them knew when to donate their eyes although $72.65 \%$ participants had awareness about eye donation, only $52.05 \%$ were willing to donate their eyes. This finding of better awareness than willingness to donate eyes is well observed in the study by Yew et al in 2005 in Singapore (awareness $80.7 \%$ and willingness only $67 \%$ ).* 
It also shows that education and religion also has a positive influence in developing awareness among participants.(5)

According to a study by Sulatha Bhandary et al in 2011, awareness of eye donation was observed in $69 \%$ participants while only $34.42 \%$ were willing to donate eyes. Awareness was more among females. While in our study, awareness is more in males $(71.56 \%)$ as males have more social exposure and sharing of information. Willingness to donate eyes was also more in males as compared to females in our study. Among those who were aware about eye donation, $68.55 \%$ participants in this study knew about no disfigurement of face whereas in the study by Sulatha Bhandary et al $76.2 \%$ knew about this.(10)

According to the study by Sulatha Bhandary et al, the most important source of awareness was the media (55.4\%) with newspapers last in the list (36.7\%). According to this study, television was the most common source of information on eye donation (46.57\%) followed by newspaper (35.61\%).(10)

In this study, majority of participants (52.06\%) thought that the whole eye is transplanted to restore vision whereas in the study by Gupta et al, 74.4\% participants knew that only cornea of the donated eyes is used for transplant.(8)

Many studies have shown that ethnicity has an important role in the willingness of organ donation. Studies show that there was poor awareness about the 'fatwa' regarding organ donation, passed by the Muslim law council in 1995. The main condition stipulated by the fatwa is that the dead person should have given his/her consent before death or his/her heirs should give their consent after his death. If neither the deceased nor heirs were identifiable, then consent of the 'Guardians of the Muslims' should be obtained.

This lack of awareness has led to the fear of doing something against religion by donating organs among population. Thus, to make this dream of reducing the burden of avoidable corneal blindness, the ophthalmologists, general physicians, NGOs and especially the religious leaders have to work together to educate and motivate people to donate eyes.

\section{CONCLUSION}

- Corneal diseases constitute a significant cause of visual impairment and blindness in the developing world. With 7.8 million blind people in India, the country accounts for $20 \%$ of the 39 million blind population across globe. Out of which $1 \%$ was due to corneal blindness.

- 636 participants were interviewed and used for analysis.
- Although people showed awareness about eye donation, they were still unwilling to donate.

- Education and gender plays a significant role in awareness about eye donation.

- Allowance of eye donation in religion was significantly associated with the motivation to donate.

- Television emerged as the major source of information.

- Education regarding eye donation should be included in syllabus to increase awareness about eye donation in community and thereby reducing burden of corneal blindness.

\section{REFERENCES}

[1] WHO visual impairment and blindness factsheet No. 282 August, 2014.

[2] Manoj A. National program for control of blindness 2012-13.

[3] Priyadarshini B, Srinivasan M, Padmavathi A, et al. Awareness of eye donation in adult population of southern India. A pilot study. Indian Journal of Ophthalmology 2003;51(1):101-4.

[4] Krishnaiah S, Kovai V, Nutheti R, et al. Awareness of eye donation in rural population of India. Indian J Ophthalmol 2004;52(1):73-8.

[5] Yew YW, Saw SM, Pan JC, et al. Knowledge and beliefs on corneal donation in Singapore adults. Br J Ophthalmol 2005;89(7):835-40.

[6] Bharti MK, Reddy SC, Tajunisah I, et al. Awareness \& knowledge on eye donation among university students. Med J Malaysia 2009;64(1):41-5.

[7] Dhaliwal U. Enhancing eye donation rates. Training students to be motivators. Indian J Ophthalmol 2002;50(3):209-12.

[8] Gupta A, Jain S, Jain T, et al. Awareness and perception regarding eye donation in students of a nursing college in Bangalore. Indian J Community Med 2009;34(2):1225 .

[9] World health assembly document A 62/7. Action plan for the prevention of avoidable blindness \& visual impairment 2009-2013. Genera, WHO press, P. 7-17.

[10] Bhandary S, Khanna R, Rao KA, et al. Eye donationawareness and willingness among attendants of patients at various clinics in Melaka, Malaysia. Indian J Ophthalmol 2011;59(1):41-5.

[11] Nekar MS, Lokare L, Gokhale SA, et al. Awareness of eye donation among college students of Hubli. IJBR 2012;3(4):201-4. 